\title{
Design of Automatic Irrigation System for Small Farmers in Rwanda
}

\author{
Gasore Geoffrey¹, Munyaneza Jean de Dieu², Ngendabanga Jean Pierre², \\ Twibanire Aimable ${ }^{2}$ \\ ${ }^{1}$ Electrical and Electronics Department, University of Rwanda-College of Science and Technology, Kigali, Rwanda \\ ${ }^{2}$ Alternative Energy Department, Tumba College of Technology, Rulindo, Rwanda \\ Email: gasoreg60@yahoo.com, g.gasore@ur.ac.rw, mujedo17@yahoo.fr, jmunyaneza@tct.ac.rw, \\ j.peter10@ymail.com, ingendabanga@tct.ac.rw, twibamable@yahoo.com, fratwibanire@tct.ac.rw
}

Received 7 February 2015; accepted 28 February 2015; published 6 March 2015

Copyright (C) 2015 by authors and Scientific Research Publishing Inc.

This work is licensed under the Creative Commons Attribution International License (CC BY). http://creativecommons.org/licenses/by/4.0/

(c) (i) Open Access

\begin{abstract}
In Rwanda, agricultural industry depends on seasonal rain, and this has been a great challenge to agriculture in Rwanda. The designed sample of Photovoltaic pumping system is for irrigation on a piece of land, with $100 \mathrm{~m}^{2}$ field fed by underground water tank of 8 meters of elevation collected during rainy seasons. The adapted $100 \mathrm{~m}^{2}$ field is based on the fact that Rwanda is a densely populated country, also is adapted to be used especially in horticulture to increase exportation. In this system, a photovoltaic system is used as a power source; a pump is coupled with electric motor to drive it and hosepipe to convey water to the storage tank. A sensor is used to send a signal to the driver section at the same time sending a signal to the microcontroller that controls the driver unit and the corresponding relay, which switches off the motor when the water level reaches the lowest level.
\end{abstract}

\section{Keywords}

Photovoltaic Water Pump, Irrigation, Automatic Control System

\section{Introduction}

Photovoltaic water pumping system is ideal in remote locations where grid electricity does not exist. All you have to do is to setup the solar system and it operates on solar power, free of charge, on its own [1] [2].

Solar pumps are powered by photovoltaic panels and the flow rate is determined by the intensity of the sunlight. Solar panels have no moving parts, and most have a warranty of at least 20 years [3] [4].

The majority of Rwandan population relies on agricultural activities. In the last years, Rwanda has been facing 
the problem of climate change resulting into changes in seasons, hence affecting farmers. This has been affecting the overall economy of the country due to lack of enough crop production. The use of solar pumping system for irrigation during dry seasons can be the best alternative way to overcome this problem.

Irrigation is not new to Rwanda. Farmers have been traditionally practicing rice irrigation by lowering the groundwater in marshlands through digging drains and creating unsaturated zones between the drains using heaped excavated soil.

The first recorded formal irrigation in Rwanda began during the colonial era in 1945 at Karongi (Kibuye District), as a response to the famine known as "Ruzagayura” (1943-1944). The 8-km and 11-km water channels were dug from a diversion on Ntaruka stream towards Rubengera which was used to irrigate people’s farms.

\section{Design of a Small Automatic Photovoltaic Pumping System for Irrigation System}

The designed sample is for a piece of land with $100 \mathrm{~m}^{2}$ field fed by underground water tank of 8 meters of elevation collected during rain seasonal to be used during dry seasonal. Pumping system has capacity of pumping 240 liters of water every day from a depth of about 8 meters.

The data required for calculation are the following

- Amount of water to be pumped per day $=240$ liter $=0.24 \mathrm{~m}^{3}$

- Total vertical lift $=(8 \mathrm{~m}-$ elevation, $3 \mathrm{~m}-$ standing water level, $2 \mathrm{~m}-$ drawdown $)=13 \mathrm{~m}$

- Water density $=1000 \mathrm{~kg} / \mathrm{m}^{3}$

- Acceleration due to gravity, $\mathrm{g}=9.8 \mathrm{~m} / \mathrm{s}^{2}$

- $\quad$ Solar PV module used $=120 \mathrm{~W}$

- Operating factor $=0.75$ (PV panel mostly does not operate at peak rated power)

- Pump efficiency $=40 \%$

- Mismatch factor $=0.85$ (PV panel does not operate at peak rated power point)

Total dynamic head

Total vertical lift $=13 \mathrm{~m}$

Friction losses $=5 \%$ of the total vertical lift $=13 \times 0.05=0.65 \mathrm{~m}$

Total dynamic head $(\mathrm{TDH})=13+0.65=13.65 \mathrm{~m} \approx 14 \mathrm{~m}$

\section{Hydraulic energy required per day}

Hydraulic energy required to raise water level $=$ density $\times$ volume $\times \mathrm{g} \times \mathrm{TDH}=\left(1000 \mathrm{~kg} / \mathrm{m}^{3}\right) \times\left(1.5 \mathrm{~m}^{3} / \mathrm{day}\right) \times$ $\left(9.8 \mathrm{~m} / \mathrm{s}^{2}\right) \times 14 \mathrm{~m}$ multiply by $1 / 3600$ to convert second in hours $=57.16 \mathrm{Watt}-\mathrm{hour} / \mathrm{day}$

\section{Solar radiation data}

Solar radiation data in terms of equivalent peak sunshine radiation $\left(1000 \mathrm{~W} / \mathrm{m}^{2}\right)$ varies between about 4.5 and 5 hours for exact hours according to meteorological data [5].

\section{Working Principle of the System}

The control circuit is supplied by 5 volts, when the IR transmitter transmit light beam to the IR receiver, is evidence that there is no obstacle between them. This is an indication that water have not reached the predetermined level at which the IR sensor is placed, with this condition, the input pin of microcontroller is always high and the output pin of microcontroller is also high. Such output will activate the base of the transistor which connects the relay to the supplying voltage, whenever the relay is supplied; it closes its contact and connects the pump to supplying voltage, 24VDC. The pump fills the water in the tank whenever the above condition is fulfilled. The red led (LED1) lights ON to indicate that the pump is pumping and on the LCD it is displayed "PUMP IS ON".

At the other turn, once the water reaches the high level, it will become an obstacle between the IR transmitter and the IR receiver, there is no beaming between them hence causing the input pin of microcontroller to be low and also its output becomes low. The current at the base of the transistor is then released. When there is no current at the base of transistor, the relay excitation voltage is automatically released, then it opens the contact and the pump is disconnected from its supplying voltage, therefore the motor stops pumping.

The Red LED is off to indicate that the pump is not pumping and on the LCD it is displayed "PUMP IS OFF".

On the other hand; when the moisture content is high $\left(\right.$ i.e. $30^{\circ} \mathrm{C}$ ) the temperature detector sends the signal to microcontroller to actuate the electro valve for irrigation. The Green LED lights ON to indicate that the irrigation is in process and on the LCD it is displayed "VALVE IS ON". 
If the moisture content of the soil is low (at temperature below $15^{\circ} \mathrm{C}$ ) the temperature detector sends the signal to microcontroller to switch off the electro valve for stopping the irrigation process. The Green LED is off to indicate that the soil is wet and on the LCD it is displayed "VALVE IS OFF".

\section{Results and Discussions}

The pump is on because the needed water level has not yet reached.

The valve is on because the temperature is more than $30^{\circ} \mathrm{C}$ and it set in microcontroller that temperature above $30^{\circ} \mathrm{C}$ is a sign of dryness in the soil.

The valve is off because the temperature is less than $30^{\circ} \mathrm{C}$ and it set in microcontroller that temperature below $30^{\circ} \mathrm{C}$ is a sign of wetness in the soil.

Figure 1 and Figure 2 show working principle, Figure 3 shows practical arrangement while Figures 4-6 show result display.

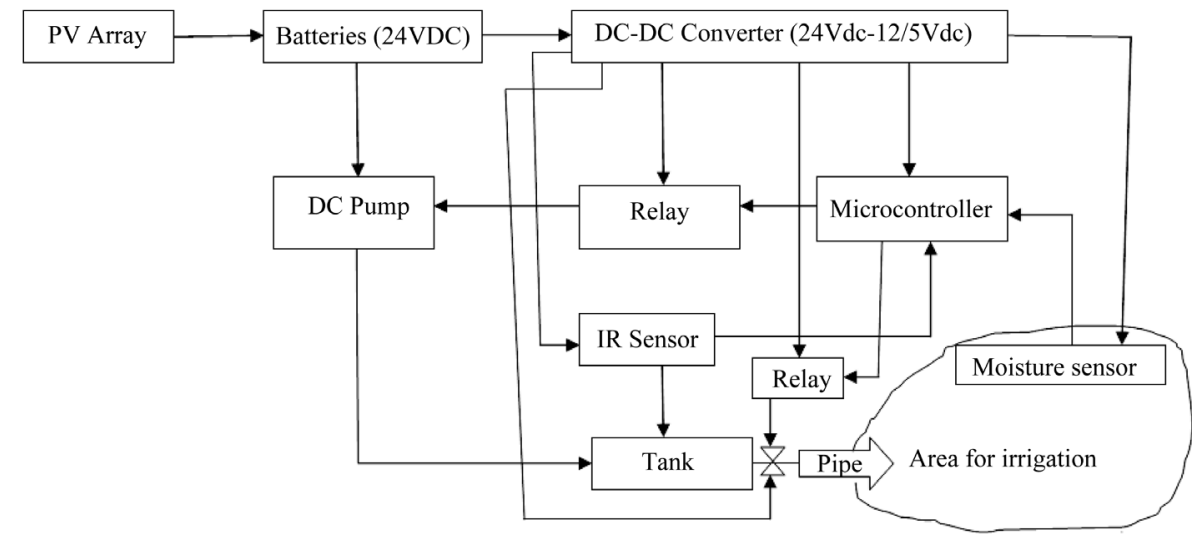

Figure 1. Block diagram of automatic solar water pumping system for irrigation.

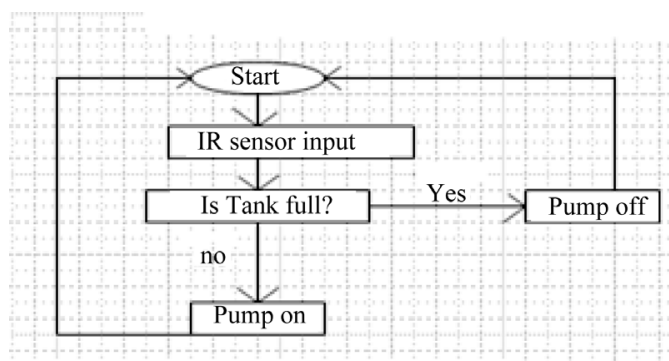

Flow chart of tank water level control

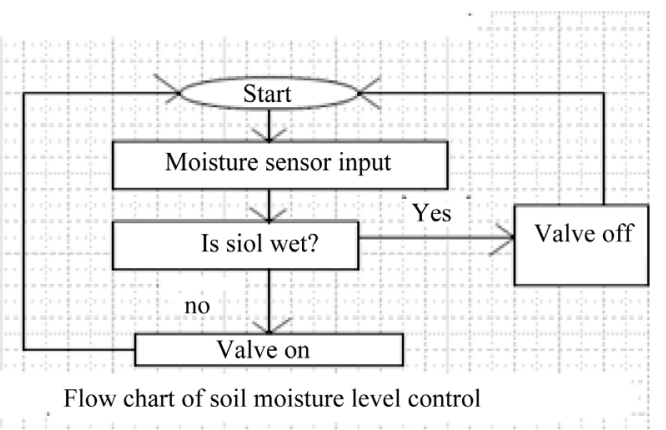

Figure 2. Flow chart of tank water level and soil moisture level control.

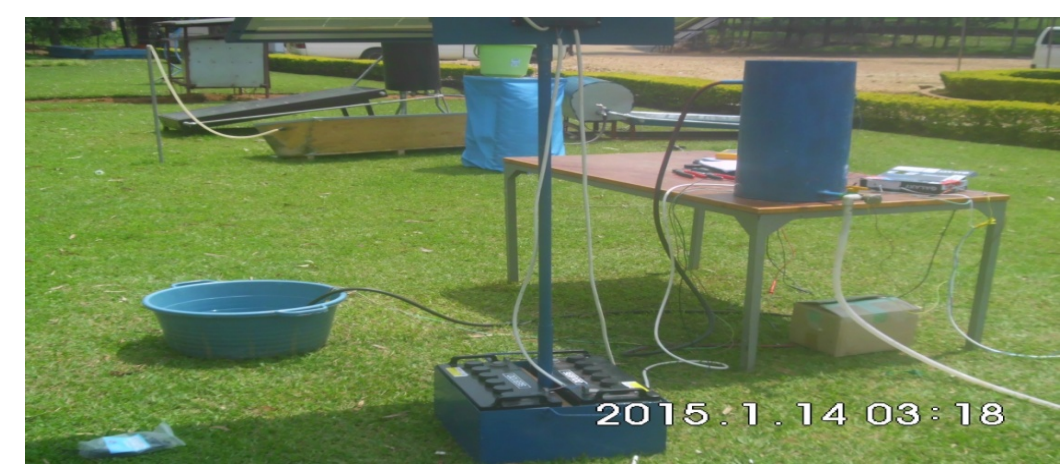

Figure 3. Test arrangement of automatic solar pumping system for irrigation. 

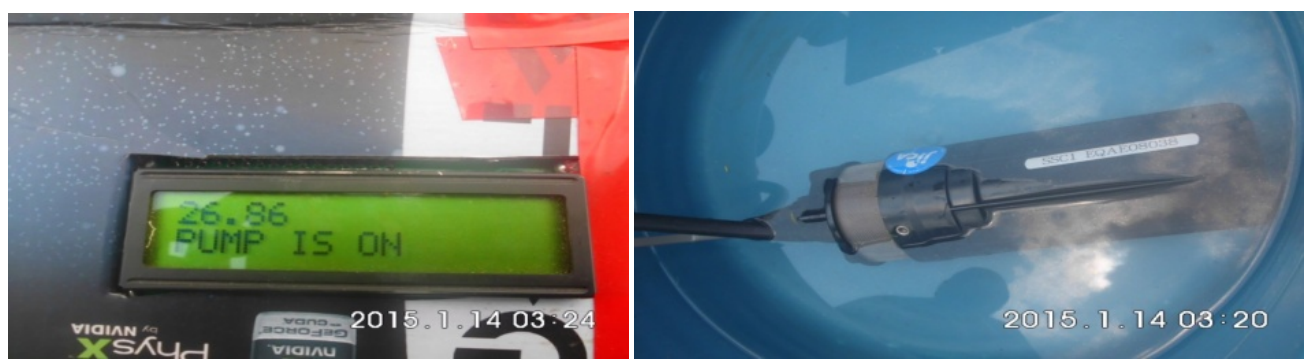

Figure 4. Pump is ON while rising water from low level to high level in the storage tank.
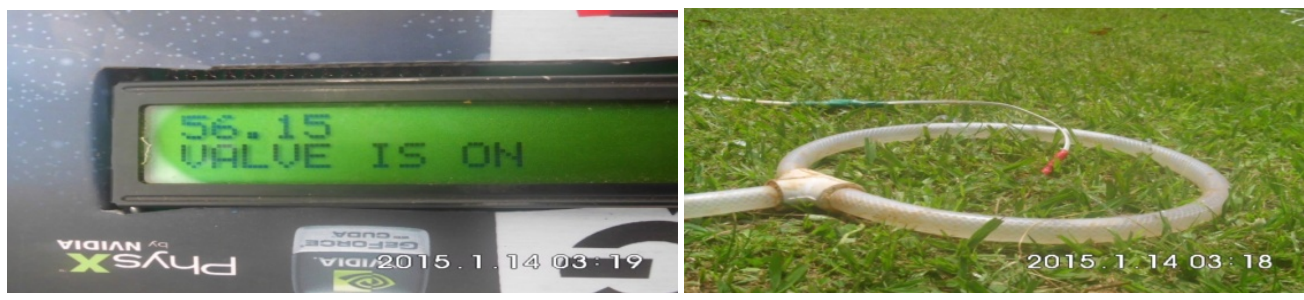

Figure 5. Valve is ON while the status soil is dry and water irrigates the soil through small holes of irrigation pipe.

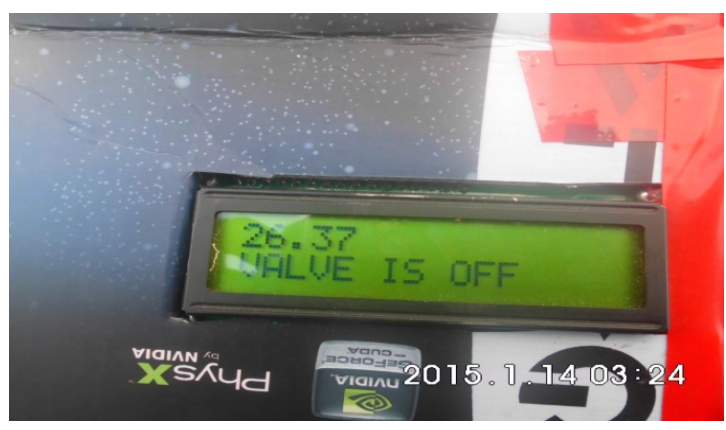

Figure 6. Valve is off.

\section{Conclusion}

This system can be adapted by many Rwandans since it is designed to work on small piece of land and many Rwandans own small pieces of land. It is also cost effective and environmentally friendly since water collection is done during rainy seasons and being collected from the residential houses and directed in underground tanks with pipes.

\section{References}

[1] Eng. Umer Mehmood. (2009) Pilot Testing of Solar Water Pumps. Lahore-Pakistan, Punjab, 2-8, $27,31$.

[2] Chris Callahan, P.E. and Waterman, B. (2013) Solar Water Pumping Basics. UVM Extension, 1-9.

[3] Morales, T.D. and Busch, J. (2010) Design of Small Photovoltaic (PV) Solar-Powered Water Pump Systems. Technical Note No. 28, United States Department of Agriculture, Washington DC, 55-71.

[4] Vick, B.D. and Clark, R.N. (2009) Determining the Optimum Solar Water Pumping System for Domestic Use or Irrigation. Proceedings of the 4th Renewable Energy Policy and Marketing Conference, 4, 132-145.

[5] Museruka, C. and Mutabazi, A. (2007) Assessment of Global Solar Radiation over Rwanda. International Conference on Clean Electrical Power, Capri, 21-23 May 2007, 670-676. 